Article

\title{
Assessment of the Capability of Sentinel-2 Imagery for Iron-Bearing Minerals Mapping: A Case Study in the Cuprite Area, Nevada
}

\author{
Wenyan Ge ${ }^{1 \oplus}$, Qiuming Cheng ${ }^{2}$, Linhai Jing ${ }^{3, *}$, Fei Wang ${ }^{4} \oplus$, Molei Zhao ${ }^{5}$ and Haifeng Ding ${ }^{3}$ \\ 1 Institute of Soil and Water Conservation, Northwest A\&F University, Xianyang 712100, China; \\ gewenyan@nwafu.edu.cn \\ 2 State Key Lab of Geological Processes and Mineral Resources, China University of Geosciences (Beijing), \\ Beijing 100083, China; qiuming.cheng@iugs.org \\ 3 Key Laboratory of Digital Earth Science, Aerospace Information Research Institute, \\ Chinese Academy of Sciences, Beijing 100094, China; dinghf@radi.ac.cn \\ 4 State Key Laboratory of Soil Erosion and Dryland Farming on the Loess Plateau, \\ Northwest Agriculture \& Forestry University, 26 Xinong Road, Xianyang 712100, China; \\ wafe@ms.iswc.ac.cn \\ 5 School of Earth Sciences and Resources, China University of Geosciences (Beijing), Beijing 100083, China; \\ moleiz@cugb.edu.cn \\ * Correspondence: jinglh@radi.ac.cn
}

Received: 26 July 2020; Accepted: 14 September 2020; Published: 17 September 2020

\begin{abstract}
With several bands covering iron-bearing mineral spectral features, Sentinel-2 has advantages for iron mapping. However, due to the inconsistent spatial resolution, the sensitivity of Sentinel-2 data to detect iron-bearing minerals may be decreased by excluding the $60 \mathrm{~m}$ bands and neglecting the $20 \mathrm{~m}$ vegetation red-edge bands. Hence, the capability of Sentinel-2 for iron-bearing minerals mapping were assessed by applying a multivariate (MV) method to pansharpen Sentinel-2 data. Firstly, the Sentinel-2 bands with spatial resolution $20 \mathrm{~m}$ and $60 \mathrm{~m}$ (except band 10) were pansharpened to $10 \mathrm{~m}$. Then, extraction of iron-bearing minerals from the MV-fused image was explored in the Cuprite area, Nevada, USA. With the complete set of 12 bands with a fine spatial resolution, three band ratios $(6 / 1,6 / 8 \mathrm{~A}$ and $(6+7) / 8 \mathrm{~A})$ of the fused image were proposed for the extraction of hematite + goethite, hematite + jarosite and the mixture of iron-bearing minerals, respectively. Additionally, band ratios of Sentinel-2 data for iron-bearing minerals in previous studies were modified with substitution of narrow near infrared band $8 \mathrm{~A}$ for band 8 . Results demonstrated that the capability for detection of iron-bearing minerals using Sentinel-2 data was improved by consideration of two extra bands and the unified fine spatial resolution.
\end{abstract}

Keywords: Sentinel-2; image fusion; iron-bearing minerals; cuprite

\section{Introduction}

As an important data support for European Union's Earth observation program, named the Copernicus Programme or Global Monitoring for Environment and Security (GMES), the Sentinel-2 mission was primarily designed for data enhancement of SPOT and Landsat missions. The Sentinel-2 mission contains two identical satellites, Sentinel-2A and Sentinel-2B, launched on 23 June 2015 and 7 March 2017, respectively. The twin satellites are in the same orbit, but at a $180^{\circ}$ opposite direction, and operate routinely now, providing data coverage from latitudes $-56^{\circ}$ to $86^{\circ}$. With a wide swath $(290 \mathrm{~km})$, fine spatial resolution and temporal resolution (5 days), Sentinel-2 imagery are being widely 
used for global monitoring since the launches, including vegetation indices extraction [1-5], wildfire detection [6-8], land cover mapping [9,10] and geological applications [11-13].

Sentinel-2 multispectral imagery (MSI) contains 13 spectral bands in the visible and near-infrared (VNIR), and short-wave infrared (SWIR) regions, with four bands at $10 \mathrm{~m}$, six bands at $20 \mathrm{~m}$ and three atmospheric correction bands at $60 \mathrm{~m}$ spatial resolution [14]. Generally, the four $10 \mathrm{~m}$ and six $20 \mathrm{~m}$ bands of Sentinel-2 imagery are used for environment monitoring $[2,6,15]$, whereas the other three $60 \mathrm{~m}$ bands were primarily designed for atmospheric correction and cloud detection (i.e., band 1 is designed for aerosol scattering and cloud detection, band 9 is mainly for aerosol retrieval and band 10 is for cloud detection) [14], which were eliminated in most studies. However, due to the electronic transitions in the iron-bearing constituent minerals, iron minerals such as goethite, hematite and jarosite exhibit diagnostic spectral features near $0.43 \mu \mathrm{m}, 0.65 \mu \mathrm{m}, 0.85 \mu \mathrm{m}$ and $0.93 \mu \mathrm{m}$, which are close to Sentinel-2 band 1 , band 4 , band 8/8A and band $9[16,17]$. Therefore, the elimination of $60 \mathrm{~m}$ Sentinel-2 bands may decrease the sensitivity of Sentinel-2 data to iron-bearing minerals in geological investigations.

Being free multispectral data, Sentinel-2 data has higher spectral resolution, spatial resolution and temporal resolution from a VNIR to SWIR range than common geological multispectral imagery, such as the Landsat series and the Advanced Spaceborne Thermal Emission and Reflection Radiometer (ASTER). In addition, the potential of Sentinel-2 imagery for geological investigations has been comprehensively discussed in previous studies $[11,12,18,19]$. For example, based on the band ratios for alteration extraction from multispectral ASTER data, van der Meer et al. [12] discussed the potential of Sentinel-2 data for geological applications. The spectral bands of Sentinel-2 imagery applied for hydrothermal alteration extraction were bands with a $10 \mathrm{~m}$ pixel size and SWIR bands [12]. Nevertheless, since the Sentinel-2 bands with $20 \mathrm{~m}$ spatial resolution in VNIR were originally designed for leaf area index, chlorophyll, water vapor absorption and atmospheric corrections [12], there were few studies on the potential of these bands for geological information extraction. Additionally, with the failure of the ASTER SWIR detector in 2008, as well as retiral of Hyperion in 2017, it is important to explore the capability of Sentinel-2 bands for geological mapping to ensure data continuity.

Image fusion methods can produce spatially enhanced multispectral (MS) images by fusing MS and panchromatic (PAN) images [20-22]. With the same coverage, the $60 \mathrm{~m}$ and $20 \mathrm{~m}$ bands of Sentinel-2 can be merged with the $10 \mathrm{~m}$ bands, offering fused bands with a cell size of $10 \mathrm{~m}$ and more spatial details [22-24]. For example, Wang et al. [22] employed three types of image fusion approaches (eight component substitution (CS), multiresolution analysis (MRA)-based approaches and area-to-point regression kriging) to pansharpen $20 \mathrm{~m}$ Sentinel-2 bands to $10 \mathrm{~m}$ cell size, yielding promising products for global monitoring. Moreover, Park et al. (2017) [25] proposed a two-step pansharpening method to enhance $20 \mathrm{~m}$ and $60 \mathrm{~m}$ Sentinel- 2 bands, and improved fusion accuracy by modifying the band combinations used in multivariate linear regression analysis. Fused Sentinel-2 imagery with $10 \mathrm{~m}$ cell size is widely applied in land-cover/land-use mapping and change detection [26,27]. However, it is rarely employed in geological surveys. Moreover, $60 \mathrm{~m}$ Sentinel-2 bands are normally ignored in image fusion due to their lower spatial resolution and the fact that their primary objective is for atmospheric correction.

In conclusion, there are still some challenges in mineral extraction based on Sentinel-2 data. For example, how to obtain bands with unified fine spatial resolution with minimized spectral distortion? What kinds of iron minerals could be identified with addition of atmospheric correction bands and $20 \mathrm{~m}$ VNIR bands? To address these questions, the Cuprite area in Nevada, a typical remote sensing geological experiment area, was chosen as the experimental region. A multivariate (MV) method [28] that was originally proposed for thermal infrared (TIR) image fusion was applied for the fusion of Sentinel-2 image to minimize spectral distortion. Moreover, the capability of fused Sentinel-2 image for iron-bearing minerals were explored by proposing new band ratios and modified original band ratios for iron minerals. 


\section{Materials and Methods}

\subsection{Sentinel-2 Data}

In this study, one $5.7 \mathrm{~km} \times 5.7 \mathrm{~km}$ L1C-level Sentinel-2A subset, acquired on August 17, 2018 and covering the Cuprite area, Nevada, USA, was chosen as the study data. The image contains 10 VNIR bands and three SWIR bands, as displayed in Table 1. The top-of-atmosphere (TOA) subset is cloud free and has been automatically atmospherically corrected to a surface reflectance product by the ATCOR model in the Sen2Cor processor algorithm provided by European Space Agency (ESA) [22].

Table 1. Some specifications of Sentinel-2 imagery [29].

\begin{tabular}{ccccc}
\hline Band & Central Wavelength $(\mathbf{n m})$ & Band Width $(\mathbf{n m})$ & Spatial Resolution $(\mathbf{m})$ & Abbreviation \\
\hline 1 & 443 & 20 & 60 & $\mathrm{MS}_{1}$ \\
2 & 490 & 65 & & $\mathrm{MS}_{1} 0_{2}$ \\
3 & 560 & 35 & 10 & $\mathrm{MS}_{3}$ \\
4 & 665 & 30 & & $\mathrm{MS}_{4}$ \\
5 & 705 & 15 & 20 & $\mathrm{MS}_{4}$ \\
6 & 740 & 15 & & $\mathrm{MS}_{5}$ \\
7 & 783 & 20 & 10 & $\mathrm{MS}_{6}$ \\
8 & 842 & 115 & 20 & $\mathrm{MS}_{7}$ \\
$8 \mathrm{~A}$ & 865 & 20 & 60 & $\mathrm{MS} 20_{8}$ \\
9 & 945 & 20 & & $\mathrm{MS}_{9}$ \\
10 & 1375 & 30 & 20 & $\mathrm{MS}_{10}$ \\
11 & 1610 & 90 & & $\mathrm{MS}_{10} 0_{11}$ \\
12 & 2190 & 180 & & $\mathrm{MS}_{12}$ \\
\hline
\end{tabular}

As illustrated by EAS [30], Sentinel-2 band 10 is an uncalibrated band, that shows noise patterns on bright images caused by detector saturation [25]. Hence, this band was neglected in the following experiments. Although designed for atmospheric correction, bands 1 and 9 were explored in the following experiments of image fusion and iron-bearing minerals detection, since they are close to the spectral features of iron-bearing minerals [17]. For the sake of brevity, several Sentinel-2 band combinations were defined as follows:

(1) $\mathrm{MS10}=\left[\mathrm{MS10}_{2}, \mathrm{MS10}_{3}, \mathrm{MS10}_{4}, \mathrm{MS10}_{8}\right]$ represents all the original $10 \mathrm{~m}$ MS bands;

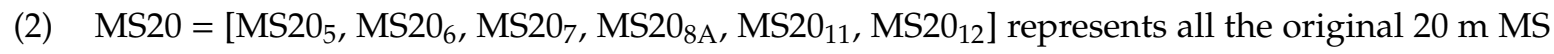
bands; and

(3) $\mathrm{MS60}=\left[\mathrm{MS} 60_{1}, \mathrm{MS60} 9\right]$ represents all the original $60 \mathrm{~m}$ MS bands.

\subsection{Image Fusion Algorithms}

In this study, two pansharpening methods, namely Gram-Schmidt (GS) and MV, were chosen as the fusion algorithms of the Sentinel-2 subset.

\subsubsection{Multivariate Method}

Based on multivariate regression analysis, a TIR image fusion method named MV was proposed by Jing et al. [28]. Different from typical image fusion, the fusion of the Sentinel-2 image in this study employs multiple high-resolution bands as the PAN in image fusion, which is similar to the TIR fusion in Jing et al. [28]. Hence, the MV method was applied for the fusion of Sentinel-2 image in this study despite of its original intention for TIR image fusion.

In the MV fusion method, the $i$ th $10 \mathrm{~m}$ Sentinel-2 band $\left(\mathrm{MS}_{1}, i=1, \ldots, 4\right)$ is degraded to an approximation $\left(M S 10_{i, L}\right)$ with a pixel size of $20 \mathrm{~m}$ or $60 \mathrm{~m}$, which was obtained by an averaging approach with a spatial resolution of $10 \mathrm{~m}$. The spatial details $\left(M S 10_{i, H}\right)$ of the $10 \mathrm{~m}$ band $M S 10_{i}$ can be defined as follows:

$$
M S 10_{i, H}=M S 10_{i}-M S 10_{i, L}
$$


A linear multivariate regression of a low-resolution $(20 \mathrm{~m} / 60 \mathrm{~m})$ band and the four $10 \mathrm{~m}$ bands of the Sentinel-2 image can be expressed as follows:

$$
M S_{\text {low }}=\sum_{i=1}^{n} a_{i} M S 10_{i}+b+e \quad i=1, \ldots, 4
$$

where $a_{i}$ and $b$ are coefficients of the multivariate regression, $e$ is the residual and $M S_{\text {low }}$ is the low-resolution $(20 \mathrm{~m} / 60 \mathrm{~m})$ band of the Sentinel-2 image, which was previously cubically up-sampled to $10 \mathrm{~m}$ pixel size.

A fused MS band is equal to the corresponding low-resolution MS band plus weighted spatial details of the high-resolution PAN image [28]. Hence, a fused band $M S_{l o w, F}$ can be obtained using coefficients $a_{i}$ obtained from Equation (2), as follows:

$$
M S_{\text {low }, \mathrm{F}}=M S_{\text {low }, L}+\sum_{i=1}^{4} a_{i} M S 10_{i, \mathrm{H}} \quad \mathrm{i}=1, \ldots, 4
$$

where $M S_{\text {low }, L}$ was the approximation with a pixel size of $20 \times 2 \mathrm{~m}$ or $60 \times 2 \mathrm{~m}$, which has a spatial resolution of $20 \mathrm{~m}$ or $60 \mathrm{~m}$ and was obtained by an averaging approach, similar to $M S 10_{i, L}$.

According to the description above, the flowchart of the MV method for Sentinel-2 image fusion is presented in Figure 1. In essence, the MV fusion method is a method based on linear multivariate analysis, in which the spatial details of the four Sentinel-2 MS10 bands are calculated and then injected into each low-resolution band (MS20/MS60) to synthesize a fused band.

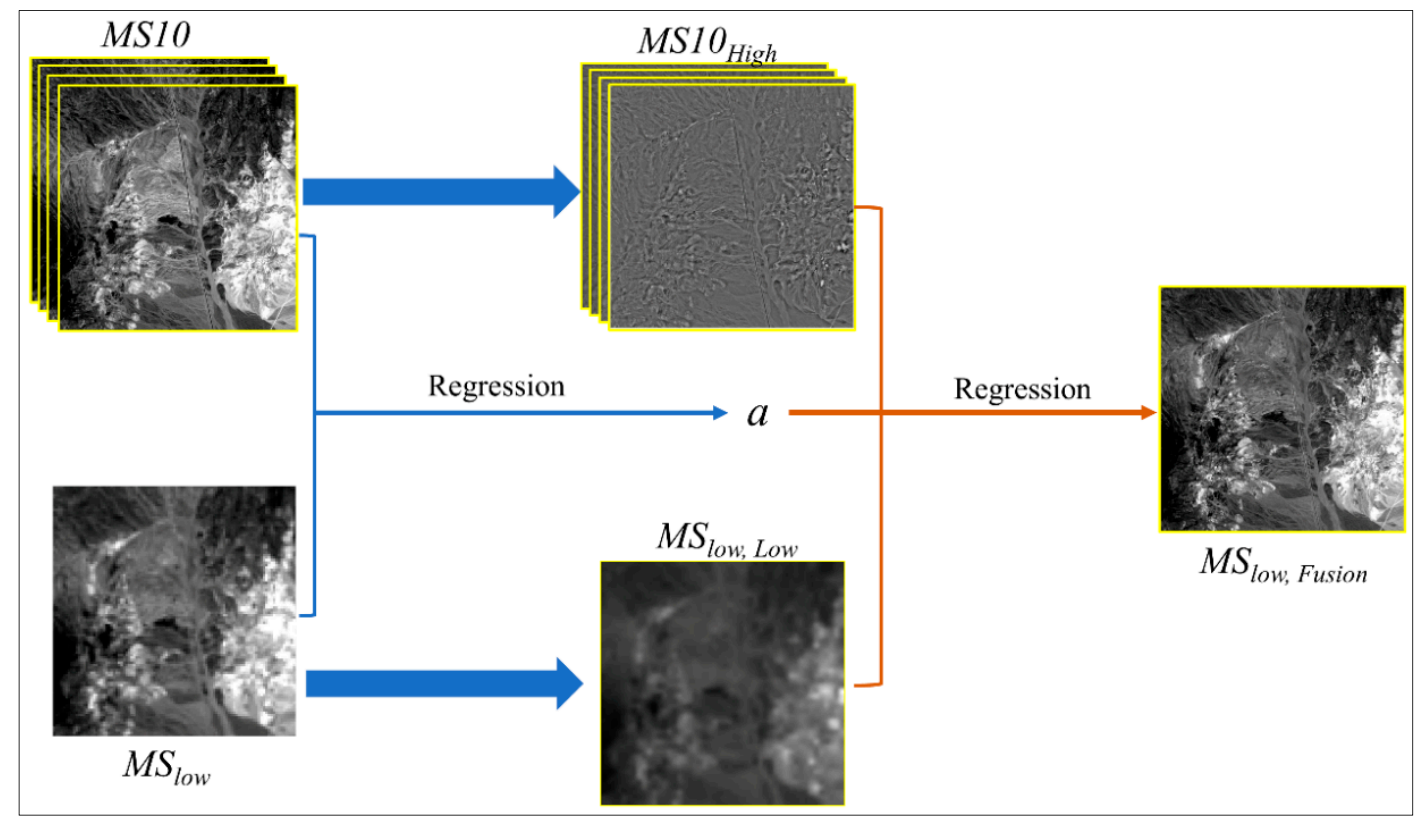

Figure 1. Flowchart of the multivariate (MV) method for Sentinel-2 image fusion. MS10 are the four original $10 \mathrm{~m}$ MS bands; $\mathrm{MS}_{\mathrm{High}}$ are the spatial details of $10 \mathrm{~m}$ band MS10; $\mathrm{MS}_{\text {low }}$ is the original $20 \mathrm{~m} / 60 \mathrm{~m}$ MS band; $M S_{\text {low }, L}$ is the approximation with a pixel size of $20 \times 2 \mathrm{~m}(60 \times 2 \mathrm{~m})$, which has a spatial resolution of $20 \mathrm{~m}(60 \mathrm{~m})$; and $M S_{\text {low, } F}$ is the fused MS20/MS60 bands with a pixel size of $10 \mathrm{~m}$.

\subsubsection{Gram-Schmidt Method}

As a representative component substitution-based image fusion method, the Gram-Schmidt (GS) method was proposed by Laben and Brower [31]. The following four steps are involved in this method [31-34]:

(1) Simulating a PAN image from the low spatial resolution spectral bands; 
(2) Performing a Gram-Schmidt transform on the low spatial resolution MS bands so that the first resultant component is the closest to the simulated PAN image;

(3) Replacing the first component by the high spatial resolution PAN image; and

(4) Performing the inverse GS transform on the new set of components to yield pansharpened MS bands.

The popular GS transform fusion method has two main advantages. Firstly, unlike Brovey and Intensity-Hue-Saturation (IHS) image fusion methods, there is no limit to the number of MS bands during fusion processing. Secondly, the spectral features in the original MS image are better preserved in the fused result [34].

Like typical image fusion methods, there is only one PAN image input in the GS image fusion. Therefore, there are two schemes to choose a high spatial resolution image from Sentinel-2 data in the fusion: (1) selecting a band according to the correlation coefficients between MS10 and other bands [24,25]; and (2) synthesizing a band through weighted combination of MS10 bands [25]. As demonstrated in Park et al. [25], the selected band scheme is better in the GS method. Therefore, in this study, one of the four MS10 bands is chosen as the PAN image for the GS fusion of the Sentinel-2 image, with reference to the correlation coefficients between MS10 and other bands.

\subsection{Quality Indices}

To assess the quality of the fused images, many indicators have been proposed for evaluating the spatial and spectral distortions of the pansharpened image [35-37]. In this study, in order to use the original MS image as a reference image to evaluate the quality of pansharpened images, the fusion experiment was performed on downsampled original images. Five indices were employed to evaluate the quality of the fused Sentinel-2 image, including correlation coefficient (R), spatial correlation coefficient (sCC), spectral angle mapper (SAM) [38], relative dimensionless global error (ERGAS) [39] and universal image quality index (UIQI) [40]. The correlation coefficient (R) numerically measures the degree of correlation of different variables as follows:

$$
R=\frac{\sum_{M} \sum_{N}\left(A_{M N}-\bar{A}\right)\left(F_{M N}-\bar{F}\right)}{\sqrt{\left(\sum_{M} \sum_{N}\left(A_{M N}-\bar{A}\right)^{2}\right)\left(\sum_{M} \sum_{N}\left(F_{M N}-\bar{F}\right)^{2}\right)}}
$$

where $A$ is the reference image, $F$ is the fused image and $M N$ is the size of the image. When $R$ is close to 1 , the lowest spectral distortion is observed and the best fusion quality is obtained.

The spectral angle mapper (SAM) measures the spectral distortion between the fused image and reference image, as defined below:

$$
\operatorname{SAM}(v, \hat{v})=\arccos \left(\frac{<v, \hat{v}>}{\|v\|_{2},\|\hat{v}\|_{2}}\right)
$$

where $v$ and $\hat{v}$ stand for the spectral pixel vectors of the reference image and the sharpened image, respectively. The optimal value of SAM is 0 .

The root mean square error (RMSE) is a measure of the differences between variables, expressed as follows:

$$
R M S E=\sqrt{\frac{\sum_{i=1}^{M} \sum_{j=1}^{N}\left[A\left(x_{i}, y_{j}\right)-F\left(x_{i}, y_{j}\right)\right]^{2}}{M \times N}}
$$

where $A$ is the reference image, $F$ is the fused image and $M$ and $N$ are the line and column of the image, respectively. When RMSE is close to 0 , the best fusion quality is obtained. 
As an improved version of the assessment index relative average spectral error (RASE), the global index of relative dimensionless global error (ERGAS) [39] is defined as below:

$$
\text { ERGAS }=100 \frac{h}{l} \sqrt{\frac{1}{K} \sum_{i=1}^{K}\left(\frac{R M S E^{2}(i)}{M E A N(i)}\right)}
$$

where $h$ and $l$ are the spatial resolutions of the PAN and MS images, respectively, $K$ is the number of bands of the fused image and MEAN $(i)$ is the mean surface reflectance of MS band $i$. The optimal value of ERGAS is 0.

The universal image quality index (UIQI) was proposed by Wang et al. [40] to assess the quality of a fused image, which is defined as follows:

$$
\mathrm{UIQI}=\frac{4 \sigma_{x y} \bar{x} \bar{y}}{\left(\sigma_{x}^{2}+\sigma_{y}^{2}\right)\left[(\bar{x})^{2}+(\bar{y})^{2}\right]}
$$

where $\bar{x}$ and $\bar{y}$ represent the sample mean values of images $\mathrm{x}$ and $\mathrm{y}$, respectively; $\sigma_{x}^{2}$ and $\sigma_{y}^{2}$ are the sample variances of images $x$ and $y$, respectively; $\sigma_{x y}$ stands for the covariance of images $x$ and $y$. The UIQI measures the similarity between two single-band images [41]. Therefore, for the Sentinal-2 image, the overall UIQI index is the average of the UIQI, obtained band by band in this study. The optimal value of UIQI is 1 .

The spatial Correlation Coefficient (sCC) was proposed to assess the spatial distortion of the fused image, by comparing the spatial details between the fused and reference images [25,42]. Firstly, a Laplacian filter is applied to both images to extract the spatial details. Then, the correlation between the two filtered images is calculated as the sCC value [25,42]. The higher the sCC is, the lower the spatial distortion in the fused image is.

\subsection{Mineral Mapping}

Iron-bearing minerals, such as hematite, jarosite and goethite, display significant absorption features from 0.4 to $1.3 \mu \mathrm{m}$ [43], as illustrated in Figure 2. Due to their similar compositions (goethite $\left[\alpha-\mathrm{Fe}^{3+} \mathrm{O}(\mathrm{OH})\right]$, hematite $\left[\alpha-\mathrm{Fe}^{3+}{ }_{2} \mathrm{O}_{3}\right]$ and jarosite $\left.\left[\mathrm{KFe}^{3+}{ }_{3}\left(\mathrm{SO}_{4}\right)_{2}(\mathrm{OH})_{6}\right]\right)$, iron-bearing minerals show analogous diagnostic spectral features in the VNIR range. As magnified in Figure $2 b, c$, jarosite and hematite show reflectance features near $0.72 \mu \mathrm{m}$ and $0.74 \mu \mathrm{m}$, respectively, both of which are close to Sentinel-2 band 6 . In addition, hematite exhibits a diagnostic absorption feature near $0.88 \mu \mathrm{m}$ corresponding to Sentinel-2A band 8A. Moreover, as explained in Swayze [43], goethite and hematite in the Cuprite area exhibit intense absorption in the 0.3-0.45 $\mu \mathrm{m}$ range, and jarosite and other similar Fe-sulfates, when forming thick coatings, show an apparent narrow diagnostic absorption near $0.43 \mu \mathrm{m}$. Therefore, with reference to these spectral features of iron-bearing minerals, two band ratios band6/band8A and band6/band1 were proposed to extract jarosite + hematite and hematite + goethite, respectively, and a band ratio (band6+band7)/band8A was proposed to extract the mixture of iron-bearing minerals including jarosite, hematite and goethite. 


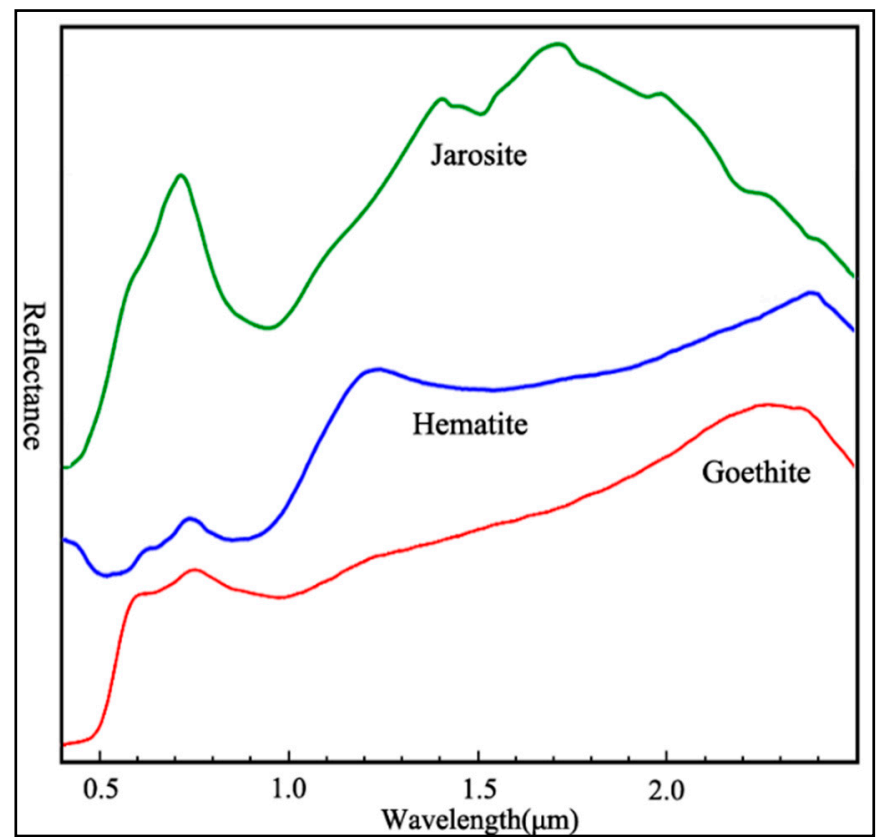

(a)

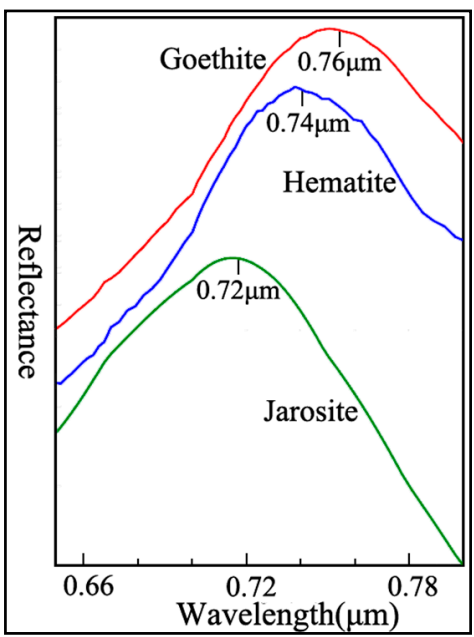

(b)

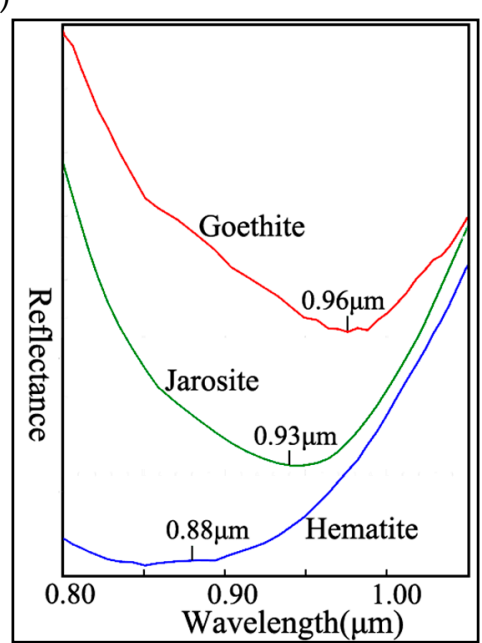

(c)

Figure 2. Spectral features of iron minerals including goethite, hematite and jarosite obtained from the United States Geological Survey (USGS) spectral library [43,44]. (a) reflectance spectra of goethite, hematite and jarosite; (b) reflectance features of iron minerals near $0.7 \mu \mathrm{m}$; (c) absorption features of iron minerals near $0.9 \mu \mathrm{m}$.

\subsection{Study Area}

The Cuprite mining district located in Nevada, USA was selected as the study area to evaluate the ability of the fused Sentinel-2 MS images for iron-bearing minerals detection. The Cuprite mining district is an arid and semi-arid region with little vegetation cover, located about $200 \mathrm{~km}$ northwest of Las Vegas, Nevada, the U.S. With plenty of well-exposed hydrothermal alteration minerals, the Cuprite area has been serving as an excellent test site for remote sensing geology for decades $[43,45-49]$.

As illustrated in Figure 3, the well-exposed hydrothermal alteration minerals of the Cuprite area are distributed around two centers on opposite sides of the Highway 95 [43,50], and can be mainly divided into three main alteration zones: a silicic alteration zone, an argillic alteration zone and an opal alteration zone. The main hydrothermal alteration minerals include hydrated silica, alunite, kaolinite, chlorite, montmorillonite and buddingtonite. Moreover, the ground truth of the iron-bearing minerals obtained from AVIRIS hyperspectral data were displayed in Figure 3c. Hematite, 
especially fine-grained to medium-grained hematite, is mainly distributed in the west of Highway 95. Other iron-bearing minerals, including goethite, jarosite, lepidocrocite and other $\mathrm{Fe}^{2+}$-bearing (ferrous iron) or $\mathrm{Fe}^{3+}$-bearing iron (ferric iron) minerals, are well-exposed in the east of the highway. Moreover, $\mathrm{Fe}^{2+}$-bearing minerals are mainly muscovites and chlorites.

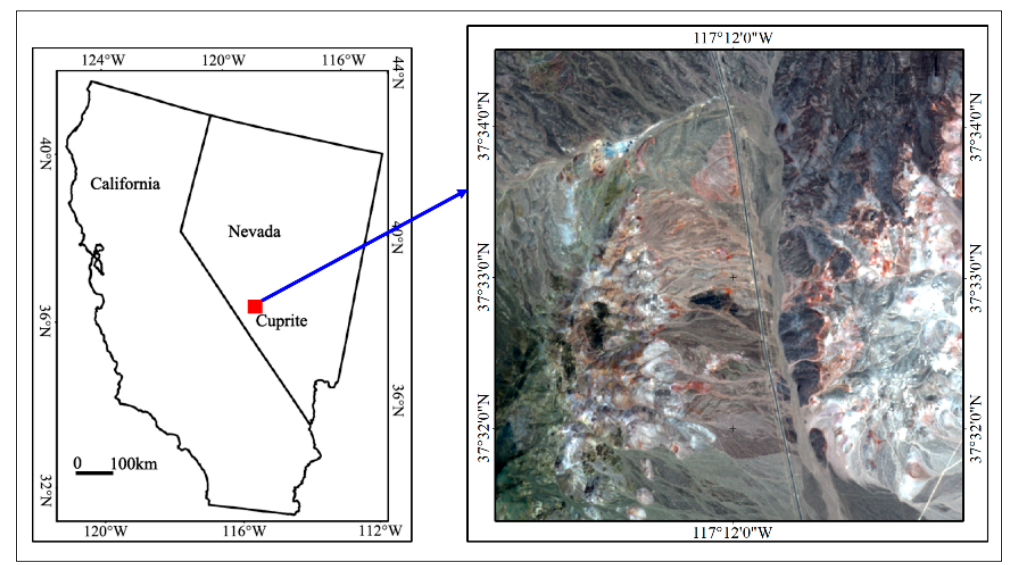

(a)

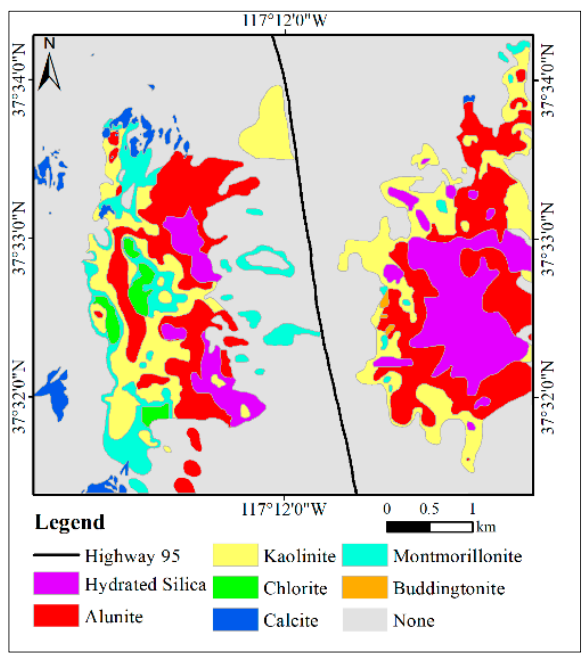

(b)

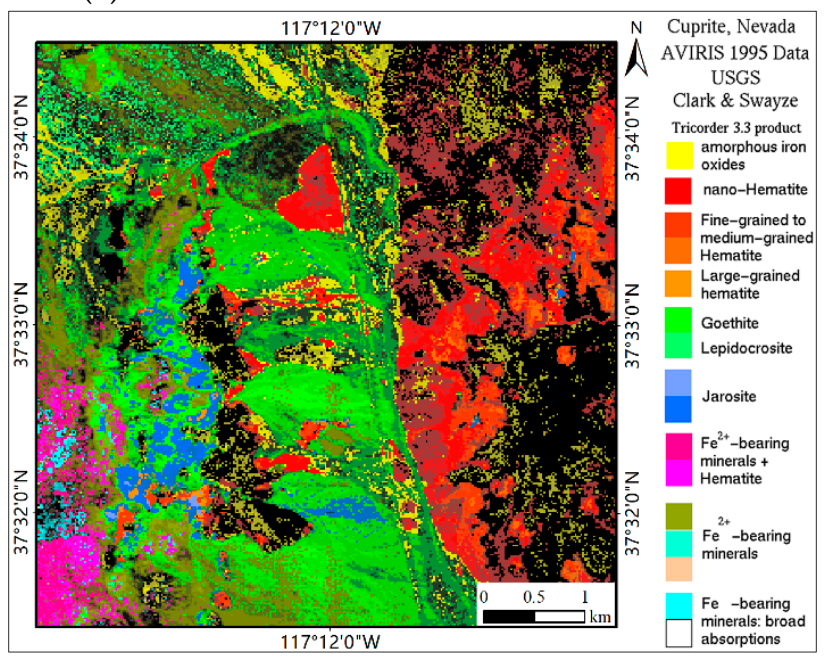

(c)

Figure 3. Location map (a), hydrothermal alteration minerals map (b) and iron-bearing minerals map (c) of the Cuprite area, modified after Mars et al. and Swayze et al. [43,48] (Map projection: WGS_1984_UTM_zone_11N).

\section{Results}

\subsection{Sentinel-2 Image Fusion}

The fused results of Sentinel-2 data using MV and GS algorithms are illustrated in Figure 4. Each fused MS image contains significantly more spatial details than the original MS images (Figure $4 a, d, g$ ). In the two fused images, small geological bodies become legible, and their boundaries are much clearer than those in the original images. For instance, the boundaries of highway 95 in Figure 4a,d,g are barely legible, whereas they can be evidently identified in the fused images. Moreover, compared with the MV fused bands (Figure 4h), the GS fused bands (Figure 4i) show more spectral distortion. 


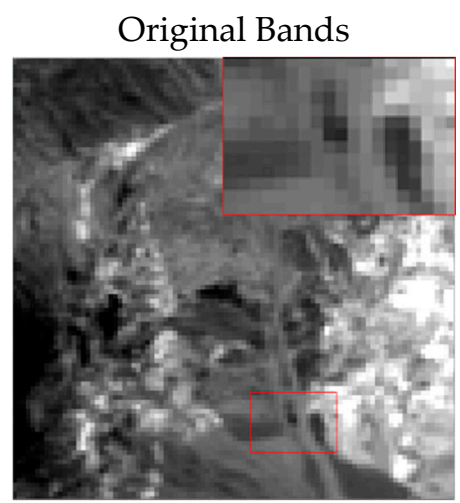

(a)

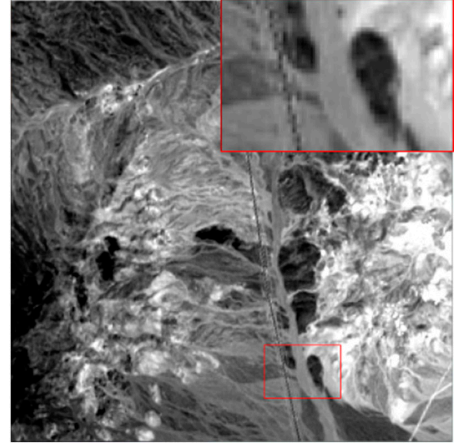

(d)

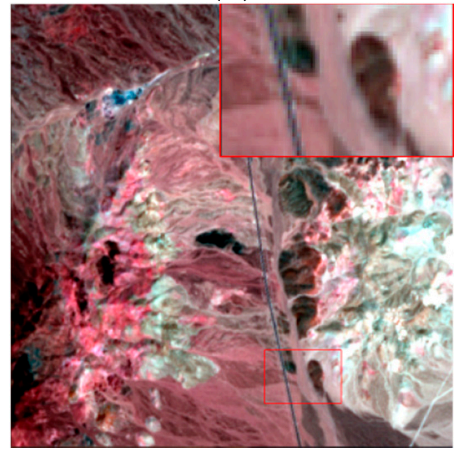

(g)

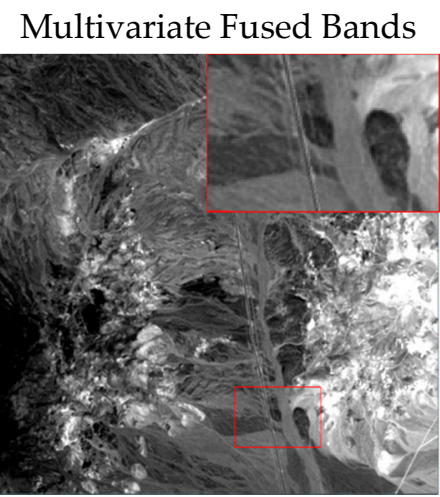

(b)

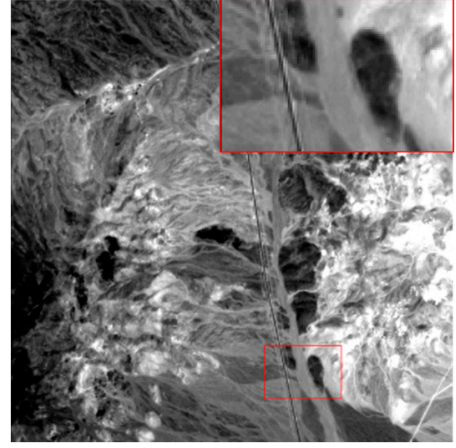

(e)

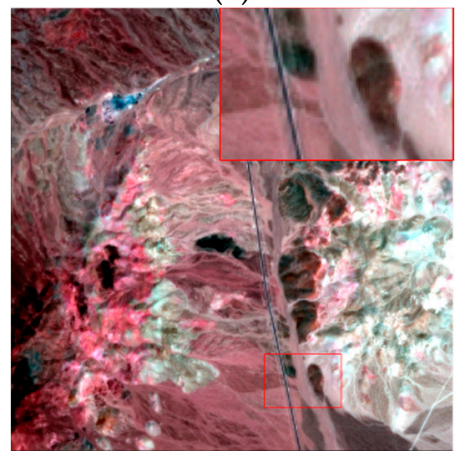

(h)

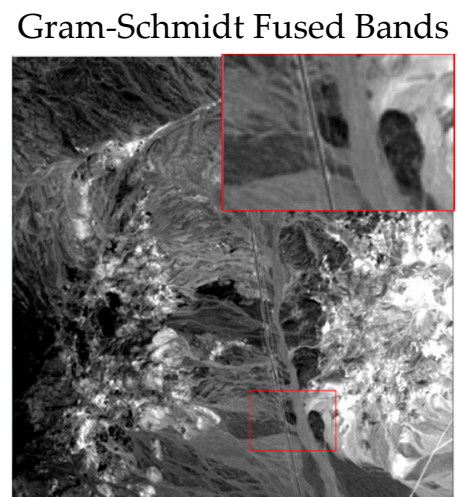

(c)

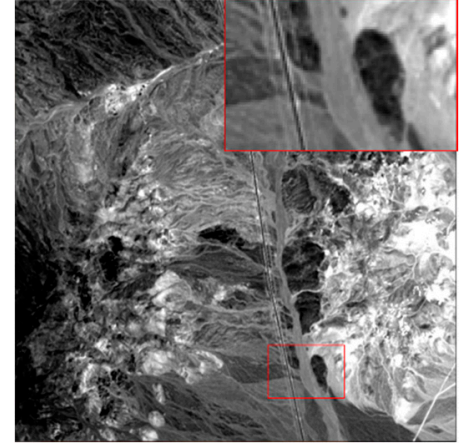

(f)

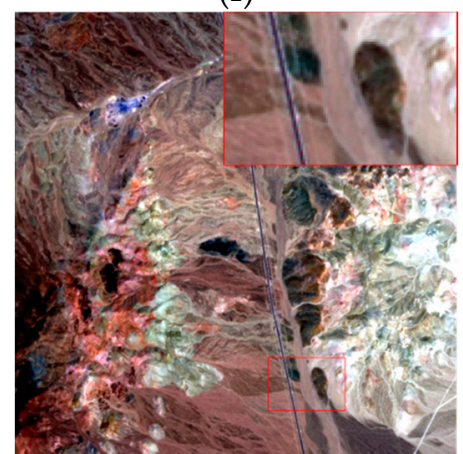

(i)

Figure 4. The original and fused Sentinel-2 bands. (a) Original $60 \mathrm{~m} \mathrm{MS60} 1$ band; (b) multivariate fused $\mathrm{MS60}_{1}$ band; (c) Gram-Schmidt fused $\mathrm{MS}_{1} 0_{1}$ band; (d) original $20 \mathrm{~m} \mathrm{MS} 2 \mathrm{O}_{6}$ band; (e) multivariate fused $\mathrm{MS}_{6} \mathrm{O}_{6}$ band; (f) Gram-Schmidt fused $\mathrm{MS}_{2} \mathrm{O}_{6}$ band; (g) original $20 \mathrm{~m}$ bands (RGB: $\mathrm{MS}_{20} \mathrm{O}_{11}-\mathrm{MS}_{2 \mathrm{~A}}-\mathrm{MS}_{2} \mathrm{O}_{5}$ ); (h) multivariate fused $20 \mathrm{~m}$ bands (RGB: MS20 ${ }_{11}-\mathrm{MS}_{2} \mathrm{O}_{8 \mathrm{~A}}-\mathrm{MS}_{2} \mathrm{O}_{5}$ );

(i) Gram-Schmidt fused $20 \mathrm{~m}$ bands (RGB: MS20 11 -MS20 8 A-MS20 5 ).

Table 2 lists the quality indices of the fused Sentinel-2 bands generated by the MV and GS pansharpening methods. Due to different spatial resolutions, the fused MS60 and MS20 bands were evaluated by quality indices separately. As shown in Table 2, the MV fused bands show a higher fused quality than those generated by the GS method except the sCC index. Conclusively, the MV method outperforms the GS algorithm on preserving the spectral quality in the fusion of Sentinel-2 bands over the Cuprite area. Therefore, the MV fused images were utilized for geological information extraction in the following subsection. 
Table 2. Quality indices of fused Sentinel-2 bands generated by the two fusion algorithms for the Cuprite area.

\begin{tabular}{lcccccc}
\hline \multirow{2}{*}{ Bands } & \multirow{2}{*}{ Method } & \multicolumn{5}{c}{ Quality Index } \\
\cline { 3 - 7 } & & R & sCC & ERGAS & SAM & UIQI \\
\hline \multirow{2}{*}{ MS60 } & MV & 0.985 & 0.933 & 0.411 & 0.377 & 0.964 \\
& GS & 0.979 & 0.945 & 0.493 & 0.488 & 0.952 \\
\hline \multirow{2}{*}{ MS20 } & MV & 0.994 & 0.907 & 0.305 & 0.454 & 0.979 \\
& GS & 0.985 & 0.912 & 0.753 & 1.658 & 0.904 \\
\hline
\end{tabular}

MV: multivariate fuse method; GS: Gram-Schmidt fuse method; MS20/MS60: bands of Sentinel-2 data with $20 \mathrm{~m} / 60 \mathrm{~m}$ spatial resolution; R: correlation coefficient; sCC: spatial correlation coefficient; ERGAS: relative dimensionless global error; SAM: spectral angle mapper; UIQI: universal image quality index.

\subsection{Hydrothermal Alteration Extraction}

In this subsection, the potentials of fused Sentinel-2 data for iron-bearing minerals extraction in the Cuprite area were explored. The distribution of the iron-bearing minerals obtained from the MV-fused Sentinel-2 image using band ratios were displayed in Figure 5. Compared with Figure 3c, the band ratio of band 6/band 8A illustrated in Figure 5a effectively discriminates hematite and jarosite in the Cuprite area (blue pixels). In addition, due to their similar diagnostic spectral features near Sentinel-2 bands 1 and 6, the band ratio of band 6/band 1 simultaneously enhances the fine-grained to medium-grained hematite and goethite as bright pixels, which are highly consistent with the ground truth obtained from AVIRIS data, as displayed in Figure 5a (red pixels). Moreover, a portion of $\mathrm{Fe}^{2+}$-bearing minerals was also identified by the band ratio of band $6 /$ band $8 \mathrm{~A}$ due to spectral features similar to jarosite and hematite. The mixture of iron-bearing minerals was extracted by a band ratio of (band $6+$ band 7)/band 8A, as red to yellow pixels (Figure 5b). Yellow to red in Figure $5 \mathrm{~b}$ represents the concentration of mixed iron-bearing minerals from low to high. The mixture of iron-bearing minerals obtained from the fused Sentinel-2 image is highly consistent with iron minerals in Figure 3c, especially for jarosite and goethite, whereas the identification of hematite on the left side of the study area was less consistent.

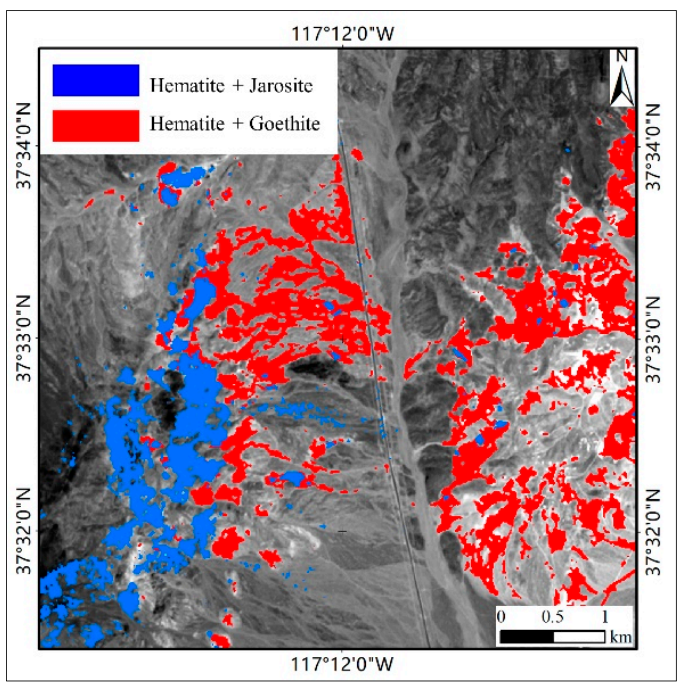

(a)

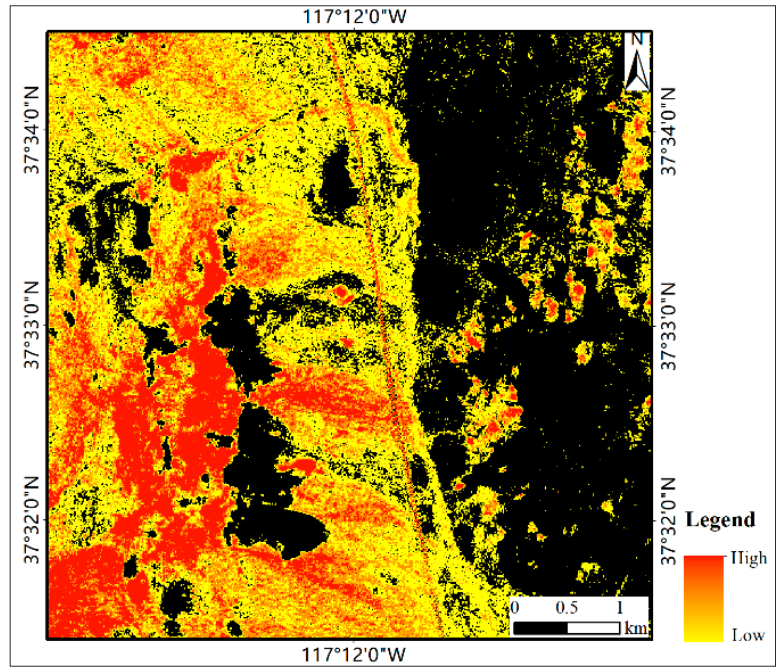

(b)

Figure 5. Distribution of iron minerals in the Cuprite area. (a) Shows the iron minerals distribution obtained from the fused Sentinel-2 data; (b) shows the mixture of iron-bearing minerals extracted from the fused Sentinel-2 data. 


\subsection{Modified Band Ratios for Mapping Iron-Bearing Minerals}

In previous studies [12,19,51], the absorption feature of iron-bearing minerals near $0.85 \mu \mathrm{m}$ was detected by band 8 instead of the narrow NIR band 8A. Nevertheless, as explained by ESA [29], the narrow NIR band 8A located at $865 \mathrm{~nm}$ was designed for vegetation extraction without contamination from water vapor, which is also sensitive to the iron oxide content of soil. In addition, the narrow NIR band $8 \mathrm{~A}$ was also demonstrated by Zhang et al. [52] to be more comparable to the Landsat-8 Operational Land Imager (OLI) NIR band 5 than band 8, as displayed in Figure 6. Moreover, $\mathrm{Fe}_{2} \mathrm{O}_{3}$ shows a higher correlation with the ferric oxide obtained from band $8 \mathrm{~A}$ than that of band 8 [53]. Therefore, with the complete set of 12 bands with a fine spatial resolution of $10 \mathrm{~m}$ in this study, the band ratios of Sentinel-2 data for iron-bearing minerals extraction proposed by van der Meer et al. [12] were modified as in Table 3.

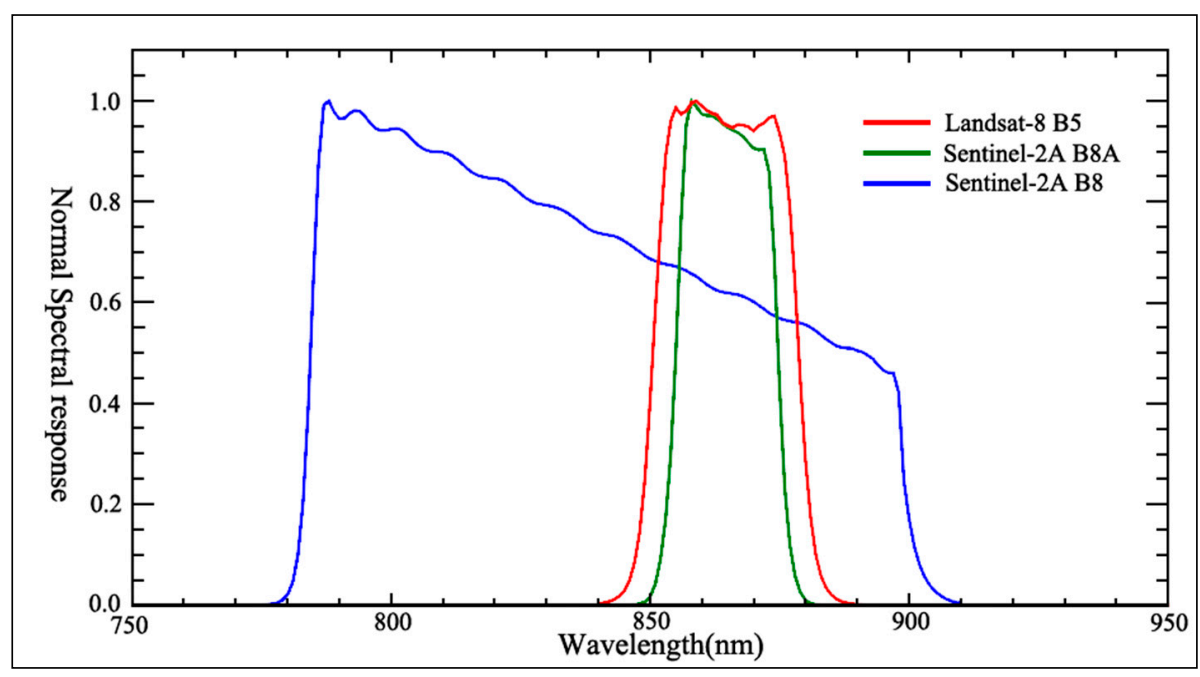

Figure 6. The comparison of spectral response functions of Landsat-8 NIR band (B5) and Sentinel-2 bands 8 and $8 \mathrm{~A}[52]$.

Table 3. Sentinel-2 data band ratios as an analogue of ASTER, Landsat 5 TM and Landsat 8 Operational Land Imager (OLI)band ratios for mapping iron-bearing minerals, modified after [12,51,54,55].

\begin{tabular}{ccccc}
\hline Feature & Landsat 5 TM & Landsat 8 OLI & Sentinel-2 & Sentinel-2(Modified) \\
\hline Ferrous iron $\left(\mathrm{Fe}^{2+}\right)$ & $7 / 4+2 / 3$ & $7 / 5+3 / 4$ & $12 / 8+3 / 4$ & $12 / 8 \mathrm{~A}+3 / 4$ \\
Ferric oxides $\left(\mathrm{Fe}^{3+}\right)$ & $5 / 4$ & $6 / 5$ & $11 / 8$ & $11 / 8 \mathrm{~A}$ \\
\hline
\end{tabular}

The scatter plots of iron-bearing minerals extracted from Landsat-8 OLI and fused Sentinel-2 images in the Cuprite area were shown in Figure 7. The correlation between the ferric oxides of Landsat-8 OLI (band ratio 6/5) and fused Sentinel-2 images is 0.852 for band ratio 11/8, whereas it is 0.903 for band ratio $11 / 8 \mathrm{~A}$. In addition, the correlation between the ferrous iron of Landsat- 8 OLI (band ratio 7/5+3/4) and fused Sentinel-2 images is 0.905 for band ratio $12 / 8+3 / 4$, whereas it is 0.937 for band ratio $12 / 8 \mathrm{~A}+3 / 4$. Results illustrated that compared with the original band ratios proposed by van der Meer et al. [12], the modified band ratios of Sentinel-2 data for iron-bearing minerals has higher consistency with those of Landsat-8 imagery. Therefore, the narrow NIR band8A of the Sentinel-2 image exhibits a better ability to extract iron-bearing minerals than band 8 . 


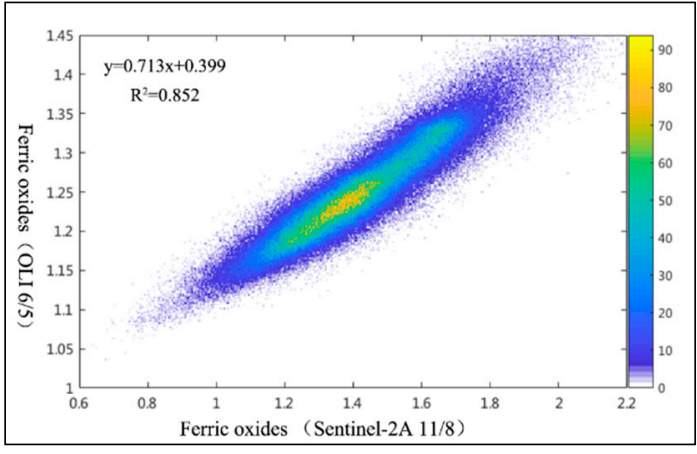

(a)

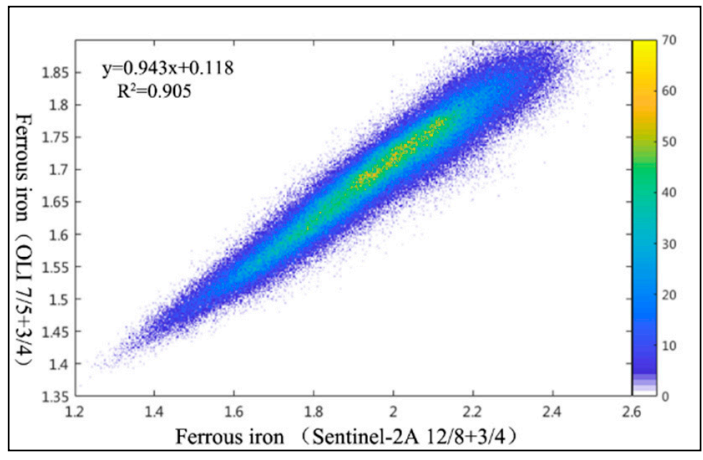

(c)

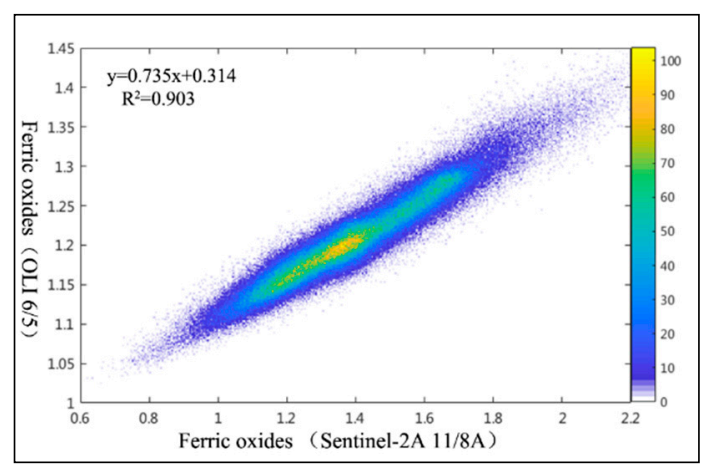

(b)

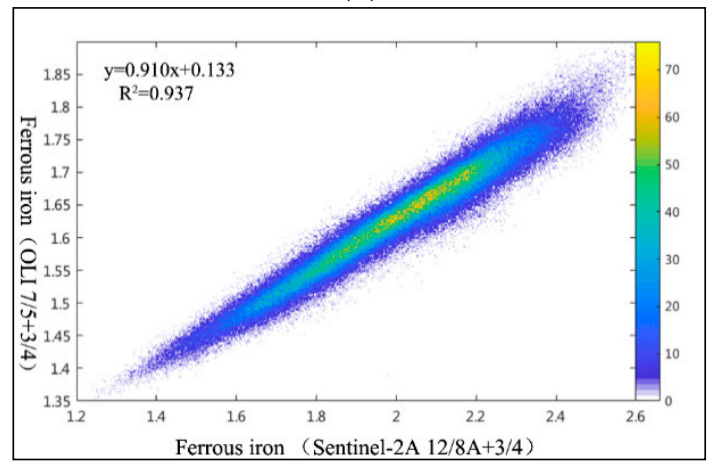

(d)

Figure 7. The scatterplots of ferric oxides and ferrous iron obtained from Landsat- 8 OLI and fused Sentinel-2 images. (a) ferric oxides obtained from band ratios OLI 6/5 and fused Sentinel-2 11/8; (b) ferric oxides obtained from band ratios OLI 6/5 and fused Sentinel-2 11/8A; (c) ferrous iron obtained from band ratios OLI 7/5+3/4 and fused Sentinel-2 12/8+3/4; (d) ferrous iron obtained from band ratios OLI $7 / 5+3 / 4$ and fused Sentinel-2 12/8A+3/4.

\section{Discussion}

Being the continuity of Landsat and SPOT, Sentinel-2 data has been widely used in earth observation, such as vegetation monitoring, land cover classification and forest fire detection $[2,3,9,15,26]$. However, due to the inconsistent spatial resolution, the ability of Sentinel-2 vegetation edge bands and atmospheric correction bands to geological mapping still lacks exploration. Hence, in this paper, to explore more deeply the capability of Sentinel-2 bands for iron-bearing mineral mapping, a multivariate regression-based image fusion method named MV was selected, and low spatial-resolution Sentinel-2 MS20 and MS60 bands were fused to $10 \mathrm{~m}$ spatial resolution. With image fusion, the spatial details were enriched in the Sentinel-2A images, sharpening object boundaries in the imagery. Furthermore, with the uniform spatial resolution of fused Sentinel-2 images, the VNIR MS20 bands could be employed for geological information extraction by combining with MS10 and SWIR bands. Moreover, with the improvement of spatial resolution, the atmospheric correlation bands

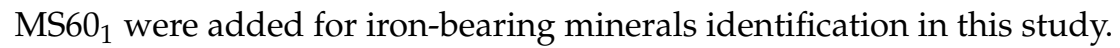

The MV-fused Sentinel-2A MS images exhibits less spectral distortion than the fused version generated using current GS pansharpening image method, as illustrated in Table 2 and Figure 4. The correlation coefficients between Sentinel-2A data MS10 bands with other bands (except band 10) were listed in Table 4, which show significant linear dependence between MS10 bands and other bands (except band 12). In addition, the multiple correlation coefficients (MCC) are higher than other correlation coefficients, as displayed in Table 4. Therefore, the MV method based on multivariate analysis shows a better capability for Sentinel-2A data fusion than the GS method. In addition, according to Jing and Cheng [28], although the Sentinel-2A band 12 has relatively lower correlation 
coefficients with MS10 bands, the fused image obtained from MV method still show high consistency with reference data.

Table 4. The linear correlation coefficients of Sentinel-2A MS10 bands with other bands.

\begin{tabular}{ccccccccc}
\hline Band & $\mathbf{1}$ & $\mathbf{5}$ & $\mathbf{6}$ & $\mathbf{7}$ & $\mathbf{8 A}$ & $\mathbf{9}$ & $\mathbf{1 1}$ & $\mathbf{1 2}$ \\
\hline $\mathbf{2}$ & 0.93 & 0.94 & 0.94 & 0.94 & 0.95 & 0.89 & 0.80 & 0.60 \\
$\mathbf{3}$ & 0.91 & 0.96 & 0.96 & 0.96 & 0.96 & 0.89 & 0.85 & 0.62 \\
$\mathbf{4}$ & 0.89 & 0.99 & 0.99 & 0.98 & 0.98 & 0.92 & 0.90 & 0.65 \\
$\mathbf{8}$ & 0.89 & 0.98 & 0.98 & 0.99 & 0.99 & 0.93 & 0.89 & 0.66 \\
MCC $^{1}$ & 0.93 & 0.99 & 0.99 & 0.99 & 0.99 & 0.94 & 0.93 & 0.68 \\
\hline \multicolumn{7}{c}{ 1 Multiple correlation coefficients. }
\end{tabular}

The MV synthetic product obtained from the Sentinel-2 image has higher spatial resolution and spectral resolution than the original Sentinel-2 data, improving its capability for the recognition of iron-bearing minerals. As illustrated in previous studies [13,43] and Figure 2, iron-bearing minerals such as goethite, hematite and jarosite have absorption features within the 0.8-0.9 $\mu \mathrm{m}$ wavelength range, which are close to Sentinel-2 bands $8 \mathrm{~A}$ and 9 . The iron minerals also show a weak reflectance feature within the $0.7-0.8 \mu \mathrm{m}$ wavelength range, which is near Sentinel-2 bands 6 and 7. Moreover, iron-bearing minerals' apparent diagnostic absorption is near $0.43 \mu \mathrm{m}$, which is close to Sentinel-2 band 1 . Hence, with the improvement of spatial and spectral resolutions by image pansharpening, it becomes possible for fused Sentinel-2 data to extract iron-bearing mineral distributions in the Cuprite area using band ratios band 6/band $8 \mathrm{~A}$, band 6/band 1 and (band $6+$ band 7 )/band $8 \mathrm{~A}$. Furthermore, the sensitivity of Sentinel-2 data for iron-bearing minerals was increased with substitution of NIR band $8 \mathrm{~A}$ for band 8 based on the enhancement in spatial resolution of band $8 \mathrm{~A}$ using MV-fused method.

As displayed in Figure 5, the distribution of iron-bearing minerals obtained from fused Sentinel-2 data is highly consistent with the ground truth provided by the United States Geological Survey (USGS). Since the diagnostic absorption of goethite $(0.96 \mu \mathrm{m})$ is far away from the central wavelength of NIR band $8 \mathrm{~A}(0.865 \mu \mathrm{m})$, band ratio 6/8A could detect hematite + jarosite from goethite well. However, due to their similar spectral features near $0.7 \mu \mathrm{m}$, the band ratio 6/8A of the fused Sentinel-2 image extracts the mixture of jarosite and hematite, and the band ratio 6/1 of the fused Sentinel-2 data extracts the mixture of hematite and goethite. Additionally, the fused Sentinel-2 data exhibits a weaker ability for iron-bearing minerals discrimination than the hyperspectral imagery of AVIRIS because of its limited spectral resolution in the VNIR and SWIR range. Moreover, the capability of Sentinel-2 for argillic alteration minerals, such as clays, micas, sulfates and carbonates, is limited because of the only two SWIR band in its band setting [12].

\section{Conclusions}

With the failure of the ASTER SWIR detectors in 2008 and inexistence of a space-borne hyperspectral system, it becomes essential to ensure data continuity for geological mapping. Thereby, in this paper, the MV method was applied to fuse the Sentinel-2 data for exploring the capability of Sentinel-2 image on iron-bearing minerals extraction in the Cuprite, Nevada. Based on the linear relationship between MS10 bands and other bands in the mulch-free area, the MV method exhibits better capability for Sentinel-2A multispectral data fusion than the common GS image pansharpening method.

With the unified spatial resolution of Sentinel-2 MS20 and MS60 bands with MS10 bands, the iron-bearing minerals including goethite + hematite and hematite + jarosite in the Cuprite area were extracted by band ratios 6/1 and 6/8A, respectively, showing high consistency with the reference map. Moreover, the mixture of iron-bearing minerals including jarosite, hematite and goethite was extracted by a band ratio (band $6+$ band 7 )/band $8 \mathrm{~A}$. Furthermore, according to the spectral features of iron-bearing minerals, the band ratios for ferric oxides and ferrous irons proposed by van der Meer et al. [8] were modified with substitution of narrow NIR band 8A for band 8, which also 
display higher correlation with those obtained from Landsat-8 OLI data. Results demonstrated that fused Sentinel-2 could be used for more accurate extraction of iron-bearing minerals because of its higher spatial and spectral resolutions.

Author Contributions: Conceptualization, W.G., Q.C. and L.J.; methodology, W.G., Q.C. and L.J.; validation, W.G., F.W. and M.Z.; formal analysis, W.G. and L.J.; investigation, W.G., M.Z. and H.D.; resources, Q.C. and L.J.; data curation, W.G. and M.Z.; writing—original draft preparation, W.G.; writing-review and editing, Q.C. and L.J.; visualization, W.G. and F.W.; supervision, Q.C. and L.J.; funding acquisition, W.G. and L.J. All authors have read and agreed to the published version of the manuscript.

Funding: This research was funded by the Doctoral Research Start-up fund of Northwest Agriculture and Forest University (No. Z1090219094), the Science and Technology Major Project of Xinjiang Uygur Autonomous Region (No. 2018A03004) and the National Natural Science Foundation of China (No. 41972308).

Acknowledgments: The authors are grateful to the United States Geological Survey (USGS) (https://glovis.usgs. gov/) and the European Space Agency (ESA) for providing research data, including OLI, Sentinel-2A data, and the reference map of the Cuprite, Nevada.

Conflicts of Interest: The authors declare no conflict of interest.

\section{References}

1. Clevers, J.G.; Gitelson, A.A. Remote estimation of crop and grass chlorophyll and nitrogen content using red-edge bands on Sentinel-2 and-3. Int. J. Appl. Earth Obs. Geoinf. 2013, 23, 344-351.

2. Delegido, J.; Verrelst, J.; Alonso, L.; Moreno, J. Evaluation of sentinel-2 red-edge bands for empirical estimation of green LAI and chlorophyll content. Sensors 2011, 11, 7063-7081. [CrossRef] [PubMed]

3. Frampton, W.J.; Dash, J.; Watmough, G.; Milton, E.J. Evaluating the capabilities of Sentinel-2 for quantitative estimation of biophysical variables in vegetation. ISPRS J. Photogramm. Remote Sens. 2013, 82, 83-92.

4. Verrelst, J.; Muñoz, J.; Alonso, L.; Delegido, J.; Rivera, J.P.; Camps-Valls, G.; Moreno, J. Machine learning regression algorithms for biophysical parameter retrieval: Opportunities for Sentinel-2 and-3. Remote Sens. Environ. 2012, 118, 127-139.

5. Vrieling, A.; Meroni, M.; Darvishzadeh, R.; Skidmore, A.K.; Wang, T.; Zurita-Milla, R.; Oosterbeek, K.; O'Connor, B.; Paganini, M. Vegetation phenology from Sentinel-2 and field cameras for a Dutch barrier island. Remote Sens. Environ. 2018, 215, 517-529.

6. Fernández-Manso, A.; Fernández-Manso, O.; Quintano, C. Sentinel-2A red-edge spectral indices suitability for discriminating burn severity. Int. J. Appl. Earth Obs. Geoinf. 2016, 50, 170-175.

7. Huang, H.; Roy, D.P.; Boschetti, L.; Zhang, H.K.; Yan, L.; Kumar, S.S.; Gomez-Dans, J.; Li, J. Separability analysis of Sentinel-2A Multi-Spectral Instrument (MSI) data for burned area discrimination. Remote Sens. 2016, 8, 873.

8. Quintano, C.; Fernández-Manso, A.; Fernández-Manso, O. Combination of Landsat and Sentinel-2 MSI data for initial assessing of burn severity. Int. J. Appl. Earth Obs. Geoinf. 2018, 64, 221-225.

9. Thanh Noi, P.; Kappas, M. Comparison of random forest, k-nearest neighbor, and support vector machine classifiers for land cover classification using Sentinel-2 imagery. Sensors 2018, 18, 18. [CrossRef]

10. Griffiths, P.; Nendel, C.; Hostert, P. Intra-annual reflectance composites from Sentinel-2 and Landsat for national-scale crop and land cover mapping. Remote Sens. Environ. 2019, 220, 135-151.

11. Ge, W.; Cheng, Q.; Tang, Y.; Jing, L.; Gao, C. Lithological classification using sentinel-2A data in the Shibanjing ophiolite complex in inner Mongolia, China. Remote Sens. 2018, 10, 638. [CrossRef]

12. Van der Meer, F.; van der Werff, H.; van Ruitenbeek, F. Potential of ESA's Sentinel-2 for geological applications. Remote Sens. Environ. 2014, 148, 124-133. [CrossRef]

13. Van der Werff, H.; van der Meer, F. Sentinel-2 for mapping iron absorption feature parameters. Remote Sens. 2015, 7, 12635-12653. [CrossRef]

14. Drusch, M.; Del Bello, U.; Carlier, S.; Colin, O.; Fernandez, V.; Gascon, F.; Hoersch, B.; Isola, C.; Laberinti, P.; Martimort, P. Sentinel-2: ESA's optical high-resolution mission for GMES operational services. Remote Sens. Environ. 2012, 120, 25-36. [CrossRef]

15. Navarro, G.; Caballero, I.; Silva, G.; Parra, P.-C.; Vázquez, Á.; Caldeira, R. Evaluation of forest fire on Madeira Island using Sentinel-2A MSI imagery. Int. J. Appl. Earth Obs. Geoinf. 2017, 58, 97-106. [CrossRef] 
16. Bishop, J.L.; Murad, E. The visible and infrared spectral properties of jarosite and alunite. Am. Mineral. 2005, 90, 1100-1107. [CrossRef]

17. Hunt, G.R.; Ashley, R.P. Spectra of altered rocks in the visible and near infrared. Econ. Geol. 1979, 74, 1613-1629. [CrossRef]

18. Mielke, C.; Boesche, N.K.; Rogass, C.; Kaufmann, H.; Gauert, C.; De Wit, M. Spaceborne mine waste mineralogy monitoring in South Africa, applications for modern push-broom missions: Hyperion/OLI and EnMAP/Sentinel-2. Remote Sens. 2014, 6, 6790-6816. [CrossRef]

19. Hu, B.; Xu, Y.; Wan, B.; Wu, X.; Yi, G. Hydrothermally altered mineral mapping using synthetic application of Sentinel-2A MSI, ASTER and Hyperion data in the Duolong area, Tibetan Plateau, China. Ore Geol. Rev. 2018, 101, 384-397. [CrossRef]

20. Li, H.; Jing, L.; Tang, Y. Assessment of pansharpening methods applied to WorldView-2 imagery fusion. Sensors 2017, 17, 89. [CrossRef]

21. Vivone, G.; Alparone, L.; Chanussot, J.; Dalla Mura, M.; Garzelli, A.; Licciardi, G.A.; Restaino, R.; Wald, L. A critical comparison among pansharpening algorithms. IEEE Trans. Geosci. Remote Sens. 2014, 53, 2565-2586. [CrossRef]

22. Wang, Q.; Shi, W.; Li, Z.; Atkinson, P.M. Fusion of Sentinel-2 images. Remote Sens. Environ. 2016, 187, $241-252$. [CrossRef]

23. Du, Y.; Zhang, Y.; Ling, F.; Wang, Q.; Li, W.; Li, X. Water bodies' mapping from Sentinel-2 imagery with modified normalized difference water index at 10 -m spatial resolution produced by sharpening the SWIR band. Remote Sens. 2016, 8, 354. [CrossRef]

24. Vaiopoulos, A.; Karantzalos, K. Pansharpening on the narrow VNIR and SWIR spectral bands of Sentinel-2. Int. Arch. Photogramm. Remote Sens. Spat. Inf. Sci. 2016, 41, 723-730. [CrossRef]

25. Park, H.; Choi, J.; Park, N.; Choi, S. Sharpening the VNIR and SWIR bands of Sentinel-2A imagery through modified selected and synthesized band schemes. Remote Sens. 2017, 9, 1080. [CrossRef]

26. Gašparović, M.; Jogun, T. The effect of fusing Sentinel-2 bands on land-cover classification. Int. J. Remote Sens. 2018, 39, 822-841. [CrossRef]

27. Zheng, H.; Du, P.; Chen, J.; Xia, J.; Li, E.; Xu, Z.; Li, X.; Yokoya, N. Performance evaluation of downscaling Sentinel-2 imagery for land use and land cover classification by spectral-spatial features. Remote Sens. 2017, 9, 1274. [CrossRef]

28. Jing, L.; Cheng, Q. A technique based on non-linear transform and multivariate analysis to merge thermal infrared data and higher-resolution multispectral data. Int. J. Remote Sens. 2010, 31, 6459-6471. [CrossRef]

29. ESA. Sentinel-2 User Handbook; ESA: Paris, France, 2015. Available online: https://sentinel.esa.int/documents/ 247904/685211/Sentinel-2_User_Handbook (accessed on 11 September 2020).

30. Clerc, S.; MPC Team. Sentinel-2 Data Quality Report; Report Issue 55; ESA-CS, France. Available online: https://sentinel.esa.int/documents/247904/685211/Sentinel-2_L1C_Data_Quality_Report (accessed on 11 September 2020).

31. Laben, C.A.; Brower, B.V. Process for Enhancing the Spatial Resolution of Multispectral Imagery Using Pan-Sharpening. U.S. Patent 6,011,875, 4 January 2000.

32. Aiazzi, B.; Baronti, S.; Selva, M.; Alparone, L. Enhanced Gram-Schmidt spectral sharpening based on multivariate regression of MS and Pan data. In Proceedings of the 2006 IEEE International Symposium on Geoscience and Remote Sensing Symposium, Denver, CO, USA, 31 July-4 August 2006; pp. 3806-3809.

33. Klonus, S.; Ehlers, M. Performance of evaluation methods in image fusion. In Proceedings of the 12th International Conference on Information Fusion, Seattle, WA, USA, 6-9 July 2009; IEEE: Piscataway, NJ, USA, 2009; pp. 1409-1416.

34. Li, C.; Liu, L.; Wang, J.; Zhao, C.; Wang, R. Comparison of two methods of the fusion of remote sensing images with fidelity of spectral information. In Proceedings of the IEEE International Geoscience and Remote Sensing Symposium, Anchorage, AK, USA, 20-24 September 2004; pp. 2561-2564.

35. Alparone, L.; Baronti, S.; Garzelli, A.; Nencini, F. A global quality measurement of pan-sharpened multispectral imagery. IEEE Geosci. Remote Sens. Lett. 2004, 1, 313-317. [CrossRef]

36. Chavez, P.; Sides, S.C.; Anderson, J.A. Comparison of three different methods to merge multiresolution and multispectral data- Landsat TM and SPOT panchromatic. Photogramm. Eng. Remote Sens. 1991, 57, $295-303$.

37. Shi, W.; Zhu, C.; Zhu, C.; Yang, X. Multi-band wavelet for fusing SPOT panchromatic and multispectral images. Photogramm. Eng. Remote Sens. 2003, 69, 513-520. 
38. Yuhas, R.H.; Goetz, A.F.; Boardman, J.W. Discrimination Among Semi-Arid Landscape Endmembers Using the Spectral Angle Mapper (SAM) Algorithm. In Summaries of the 4th JPL Airborne Earth Science Workshop; JPL Publication, Summaries of the Third Annual JPL Airborne Geoscience Workshop; NASA: Washington, DC, USA, 1992; pp. 147-149.

39. Wald, L. Data Fusion: Definitions and Architectures-Fusion of Images of Different Spatial Resolutions; Presses des Mines: Paris, France, 2002.

40. Wang, Z.; Bovik, A.C. A universal image quality index. IEEE Signal Process. Lett. 2002, 9, 81-84. [CrossRef]

41. Wei, Q.; Bioucas-Dias, J.; Dobigeon, N.; Tourneret, J.-Y. Hyperspectral and multispectral image fusion based on a sparse representation. IEEE Trans. Geosci. Remote Sens. 2015, 53, 3658-3668. [CrossRef]

42. Mahyari, A.G.; Yazdi, M. Panchromatic and multispectral image fusion based on maximization of both spectral and spatial similarities. IEEE Trans. Geosci. Remote Sens. 2011, 49, 1976-1985. [CrossRef]

43. Swayze, G.A.; Clark, R.N.; Goetz, A.F.; Livo, K.E.; Breit, G.N.; Kruse, F.A.; Sutley, S.J.; Snee, L.W.; Lowers, H.A.; Post, J.L. Mapping advanced argillic alteration at Cuprite, Nevada, using imaging spectroscopy. Econ. Geol. 2014, 109, 1179-1221. [CrossRef]

44. Crowley, J.; Williams, D.; Hammarstrom, J.; Piatak, N.; Chou, I.-M.; Mars, J. Spectral reflectance properties $(0.4-2.5 \mu \mathrm{m})$ of secondary Fe-oxide, Fe-hydroxide, and Fe-sulphate-hydrate minerals associated with sulphide-bearing mine wastes. Geochem. Explor. Environ. Anal. 2003, 3, 219-228. [CrossRef]

45. Rowan, L.C.; Wetlaufer, P.H.; Goetz, A.F.; Stewart, J. Discrimination of rock types and detection of hydrothermally altered areas in south-central Nevada by the use of computer-enhanced ERTS images. Geol. Surv. Prof. Pap. 1976, 883, 35.

46. Kruse, F.; Kierein-Young, K.; Boardman, J. Mineral mapping at Cuprite, Nevada with a 63-channel imaging spectrometer. Photogramm. Eng. Remote Sens. 1990, 56, 83-92.

47. Kruse, F.A. Mineral mapping with AVIRIS and EO-1 Hyperion. In Proceedings of the 12th JPL Airborne Geoscience Workshop, Pasadena, CA, USA, 24-28 January 2003; Jet Propulsion Laboratory: Pasadena, CA, USA, 2003; Volume 41, pp. 149-156.

48. Mars, J.C.; Rowan, L.C. Spectral assessment of new ASTER SWIR surface reflectance data products for spectroscopic mapping of rocks and minerals. Remote Sens. Environ. 2010, 114, 2011-2025. [CrossRef]

49. Kruse, F.A.; Perry, S.L. Mineral mapping using simulated Worldview-3 short-wave-infrared imagery. Remote Sens. 2013, 5, 2688-2703. [CrossRef]

50. Ashley, R.P. Alteration mapping Using Multispectral Images-Cuprite Mining Districts, Esmeralda County, Nevada. US Geol. Surv. Open File Rep. 1980, 80-367.

51. Van der Werff, H.; van der Meer, F. Sentinel-2A MSI and Landsat 8 OLI provide data continuity for geological remote sensing. Remote Sens. 2016, 8, 883. [CrossRef]

52. Zhang, H.K.; Roy, D.P.; Yan, L.; Li, Z.; Huang, H.; Vermote, E.; Skakun, S.; Roger, J.-C. Characterization of Sentinel-2A and Landsat- 8 top of atmosphere, surface, and nadir BRDF adjusted reflectance and NDVI differences. Remote Sens. Environ. 2018, 215, 482-494. [CrossRef]

53. Ibrahim, E.; Barnabé, P.; Ramanaidou, E.; Pirard, E. Mapping mineral chemistry of a lateritic outcrop in new Caledonia through generalized regression using Sentinel-2 and field reflectance spectra. Int. J. Appl. Earth Obs. Geoinf. 2018, 73, 653-665. [CrossRef]

54. Sabins, F.F. Remote sensing for mineral exploration. Ore Geol. Rev. 1999, 14, 157-183. [CrossRef]

55. Kalinowski, A.; Oliver, S. ASTER mineral index processing manual. Remote Sens. Appl. Geosci. Aust. 2004, 37, 36. 